\title{
Spectinomycin hydrochloride in the treatment of uncomplicated gonorrhoea
}

\author{
CHALMERS E. CORNELIUS III* AND GERALD DOMESCIK† \\ From the Venereal Disease Branch, National Communicable Disease Center, U.S. Public Health Service, \\ Atlanta, Georgia, U.S.A.
}

In 1960 spectinomycin, a new broad spectrum antibiotic, was released for clinical investigation and it was shown that the administration of $2 \mathrm{~g}$. of the sulphate salt was effective therapy in acute gonorrhoea yielding cure rates of approximately 87 to 95 per cent. in males. The cure rate in females was 92 per cent. with a 3 g. dose (Laird and Taylor, 1962; Willcox, 1963; Tiedemann, Hackney, and Price, 1965; Sparling, Yobs, Billings, and Hackney, 1966). In order to provide a more concentrated suspension for parenteral administration, a new hydrochloride salt has now been developed; it is the purpose of this paper to report the results of the administration of

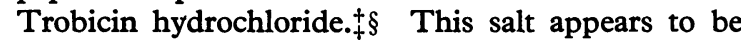
more effective than spectinomycin sulphate in the treatment of acute gonorrhoea.

\section{Material and Methods}

Male patients with uncomplicated gonococcal urethritis and female patients with uncomplicated genital infection diagnosed at the Fulton County Health Department, Atlanta, Georgia, were selected for this study, which was conducted from October 1, 1968, to March 31, 1969. Patients below the age of puberty were excluded.

Males A diagnosis of gonococcal urethritis was made in cases of frank purulent urethral discharge which revealed Gram-negative intracellular diplococci with the typical morphology of $N$. gonorrhoeae.

Females The diagnosis of gonorrhoea was based on the following cultural technique:

Received for publication September 23, 1969

*Assistant to the Chief of the Venereal Disease Branch

tAssigned to the Fulten County Health Department in Atlanta, Georgia

¥Trade names are used for the identification only and do not represent endorsement of the United States Public Health Service or of the U.S.

Department of Health, Education, and Welfare

SThis antibiotic is not available in the United Kingdom
Specimens taken with sterile cotton swabs from the cervix, vagina, and rectum were inoculated onto ThayerMartin (TM) selective media (Thayer and Martin, 1964). These cultures were incubated at $34.5^{\circ} \mathrm{C}$. in an atmosphere of 2 per cent. $\mathrm{CO}_{2}$ and identified at 24 to $48-\mathrm{hr}$ intervals. Presumptive diagnosis of infection by $N$.gonorrhoeae was made on the basis of the colony morphology, the oxidase reaction, and the Gram stain appearances.

Treatment The male patients and the first forty female patients were treated with a single intramuscular injection of $2 \mathrm{~g}$. spectinomycin hydrochloride. The remaining women received a $4 \mathrm{~g}$. dose, divided between two injection sites. All patients were told to return in 2 days.

Examination for cure This was performed 48 to $96 \mathrm{hrs}$ after treatment. Intraurethral specimens were taken from male patients by gentle scraping with a sterile platinum loop and inoculated onto TM medium. Cervical, vaginal, and rectal specimens from female patients were cultured as already described.

\section{Results}

The results of this study are summarised in the Table.

Of 165 men treated, 108 returned for examination and there were no cases of treatment failure.

Of the forty women treated with $2 \mathrm{~g}$. doses, 29 were followed; the only patient from whom a positive culture was obtained admitted exposure to risk of infection during the observation period. If this case is considered to be a re-infection, the cure rate for the remaining 28 cases is 100 per cent.

Among the 108 women who received 4 g., 67 of the 71 who returned for examination yielded negative results to cultures. Of the four in whom a positive culture was obtained after treatment, one was judged a re-infection on a history of further intercourse and three were considered to be due to failure of

TABLE Results of treatment with spectinomycin hydrochloride

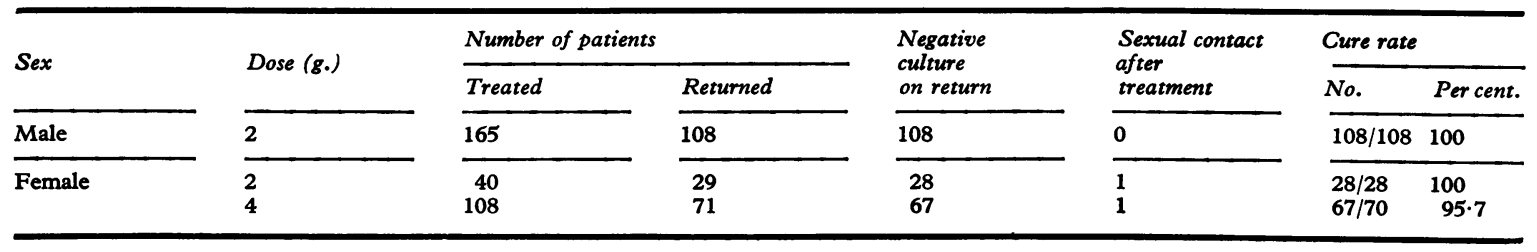


treatment. These three patients did not differ from those in the cured group by virtue of the severity or duration of infection or the number of previous infections. The final cure rate among the female cases treated with $4 \mathrm{~g}$. was, therefore, 67 of $70(95.7$ per cent.).

\section{Discussion}

Cultures and fermentation reactions were not carried out in the male cases, but the possibility of a gonorrhoea-like urethritis due to Mima polymorpha var. oxidans is extremely remote. In the many studies performed by the Neisseria division of the National Communicable Disease Center in the past 30 years, there has been no case of urethritis attributable to this organism, nor has any other investigative group been able to provide the Center with bacteriological proof that this organism produces urethritis.

Of the 42 different drugs studied at the Fulton County Health Department in Atlanta between 1962 and 1969, spectinomycin hydrochloride appears to be one of the most effective for the treatment of acute gonorrhoea. It is difficult to give a comparison of the effectiveness of various drugs used in the treatment of gonorrhoea unless studies are done in the same population simultaneously; there are strains of gonococci with varying degrees of resistance to different antibiotics and the distribution of these resistant strains varies both in time and geographically. Another important problem in drug evaluation is the establishment of cure. Testing the patient 48 to $96 \mathrm{hrs}$ after treatment is not ideal, because an antibiotic may suppress the infection so that the patient appears to be asymptomatic and a negative culture obtained. On the other hand, if a longer follow-up period is used, patients such as those attending the Fulton County Clinic frequently fail to return or present the possibility of re-infection. It has been the experience of the authors that, if the patient has a negative culture result 48 to $96 \mathrm{hrs}$ after therapy and does not return for re-treatment within the next 7 days, he can be considered to be cured of his disease.

The U.S. Public Health Service (1968) recommendation for the treatment of gonorrhoea in females, based on several clinicial studies (Shapiro, Lentz, and MacVicar, 1967; Lucas, Price, Thayer, and Schroeter, 1967) calls for the administration of 4.8 million units aqueous procaine penicillin $G$, which is twice the recommended dosage for males. Undoubtedly, the administration of larger doses of penicillin yields greater cure rates for both sexes, but whether gonococcal infection in the female is of such a nature that it needs twice the dosage required for male cases is questionable. Certainly, the idea of doubling the dosage of antibiotics other than penicillin needs investigation.
In the men and women treated with $2 \mathrm{~g}$. spectinomycin hydrochloride, there were no failures, whereas, in the group of women treated with $4 \mathrm{~g}$. there was a 4.3 per cent. failure rate. Although the number of women treated with $2 \mathrm{~g}$. was small, the findings suggest it may not be necessary to double the dose of spectinomycin hydrochloride which is effective in males in order to eradicate the infection in females.

\section{Summary}

Spectinomycin hydrochloride, a new salt of spectinomycin, was used in the treatment of acute uncomplicated gonorrhoea in both men and women. A dose of 2 g. yielded a 100 per cent. cure rate in 108 men and 28 women. In a group of seventy women treated with $4 \mathrm{~g}$. there was a failure rate of 4.3 per cent. It is considered that spectinomycin hydrochloride is one of the most effective drugs for the treatment of gonorrhoea. The authors doubt the need to give to women double the dose effective in male cases.

\section{References}

LAIRD, S. M., and TAYLOR, G. (1962) Brit. F. vener. Dis., 38, 60

Lucas, J. B. Price, E. V., Thayer, J. D., and Schroeter, A. (1967) New Engl. f. Med., 276, 1454

Shapiro, L. H., Lentz, J. W., and MacVicar, D. N. (1967) Obstet. and Gynec., 30, 89

Sparling, P. F., Yobs, A. R., Billings, T. E., and HACKNEY, J. F. (1966) "Spectinomycin Sulfate and Aqueous Procaine Penicillin G in the Treatment of Female Gonorrhoea", in "Antimicrobial Agents and Chemotherapy-1965", ed. G. L. Hobby, p. 689

Thayer, J. D., and Martin, J. E. (1964) Publ. Hlth Rep. (Wash.), 79, 49

Tiedemann, J. H., Hackney, J. F., and Price, E. V. (1965) F. Amer. med. Ass., 191, 89

Wirlcox, R. R. (1963) Acta derm.-venereol. (Stockh.), 43, 399

U.S. Department of Health, Education and Welfare (1968) "Gonorrhoea: Interim Recommended Treatment Schedule, May, 1968". U.S. Public Health Service

Le chlorhydrate de spectinomycine dans le traitement de la gonococcie non compliquée

\section{SOMMAIRE}

Un nouveau sel de spectomycine, le chlorhydrate, a été employé dans le traitement de la gonococcie aigüe non compliquée, tant chez l'homme que chez la femme. Une dose de $2 \mathrm{~g}$. a permis un taux de guérison de 100 pour cent chez 108 hommes et 28 femmes. Dans un groupe de $\mathbf{7 0}$ femmes traitées par $\mathbf{4}$ g., le taux d'insuccès fut de 4,3 pour cent. On considère que le chlorhydrate de spectomycine est un des médicaments les plus efficaces dans le traitement de la gonococcie. Les auteurs mettent en doute la nécessité de donner aux femmes le double de la dose efficace chez l'homme. 